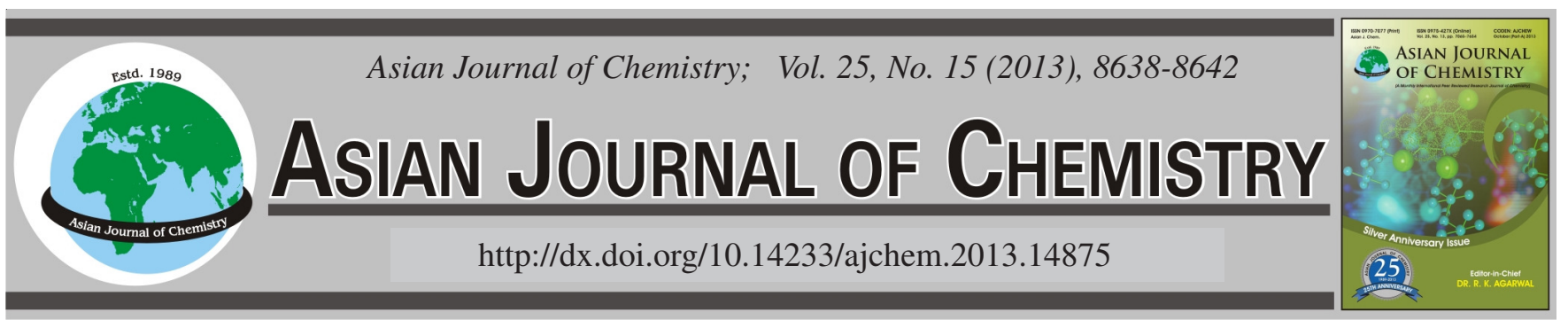

\title{
Comparative Study of the Cure and Mechanical Properties of Natural Rubber/Expandable Graphite Vulcanizate Filled with Nano and Precipitated Calcium Carbonate
}

\author{
SheEla S. Fernandez and Sam Kunchandy
}

Department of Chemistry, S.N. College, Chengannur, Alappuzha-689 508, India

*Corresponding author: Tel: +91 479 2360140; E-mail: sheelafernandez62@gmail.com

\begin{abstract}
A comparative study was performed of nano- $\mathrm{CaCO}_{3}$ and precipitated calcium carbonate as fillers in natural rubber/expandable graphite vulcanizates. A number of vulcanizates with different loadings of the fillers were prepared using a two-roll mill and moulded on a compression moulding machine. Effects of filler dosage on the cure and mechanical properties of the flame retardant natural rubber/ expandable graphite vulcanizates were examined. Because of the reduction in the size of the nano $\mathrm{CaCO}_{3}$, drastic improvement in the mechanical properties were found in comparison with precipitated calcium carbonate filled natural rubber/expandable graphite composites. Furthermore, cure properties showed that nano $\mathrm{CaCO}_{3}$ filled natural rubber vulcanizates exhibited lower cure time than the precipitated calcium carbonate filled natural rubber/expandable graphite vulcanizates. The values of the swelling ratio of the nano $\mathrm{CaCO}_{3}$ filled vulcanizates decreased remarkably and are lower than the precipitated calcium carbonate filled natural rubber vulcanizates. There is an indication that that the optimum level of incorporation of nano $\mathrm{CaCO}_{3}$ is $6 \mathrm{phr}$.
\end{abstract}

Key Words: Vulcanizates, Natural rubber, Expandable graphite, $\mathrm{Nano} \mathrm{CaCO}_{3}$, Mechanical properties.

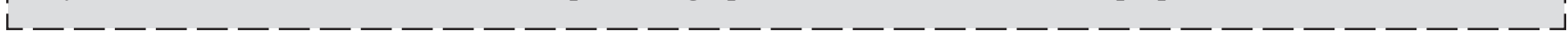

\section{INTRODUCTION}

There are increased efforts worldwide in establishing and sustaining high level of fire safety in consumer products. Since natural rubber (NR) is widely used in various applications such as housing, automobiles and electrical appliances, it is of utmost importance that its flammability should be reduced. Derouet et al., attempted to improve the flame retardancy of natural rubber by the incorporation of the phosphorus modified epoxidized liquid natural rubber in to $\mathrm{it}^{1}$. Ramesan reported that dichlorocarbene modified styrene butadiene rubber as well as its blends with natural rubber showed better thermal stability and flame resistance ${ }^{2}$. The use of halogen containing flame retardants has been limited because they generate toxic and corrosive fumes creating environmental problems. Expandable graphite (EG), a new generation intumescent flame retardant (IFR) with particular char-yielding properties have been widely used in various polymeric materials such as polyolefins ${ }^{3,4}$, polymethylmethacrylate ${ }^{5}$, polyurethanefoam ${ }^{6}$, polyamide $^{7}$, acrylonitrile butadiene rubber $(\mathrm{NBR})^{8,9}$, polyesters ${ }^{10,11}$ etc. to impart flame retardant properties. Expandable graphite is an intercalated material, prepared by treating natural graphite flakes with a solution of sulphuric and nitric acid. The crystal structure of expandable graphite undergoes intumescence and expands as much as 100 times in the c-direction upon exposure to high temperature and helps in slowing down heat and mass transfer between the gas and condensed phase and thus prevents the underlying polymeric substrate from further attack by heat flux ${ }^{12-14}$. It has been observed by several authors that the particle size, volume expansion ${ }^{15,16}$ and the loading of expandable graphite $^{17}$ in the polymer matrix plays a crucial role in the flame retardant properties of the vulcanizates. Though micron sized expandable graphite particles are promising intumescent flame retardant for polymers, inclusion of micron sized expandable graphite or its higher loadings in polymer formulation, degrades the mechanical properties of the product ${ }^{18-20}$.

Nanosized $\mathrm{CaCO}_{3}$ is a low-cost commercially available nanofiller and is able to impart significant improvements of specific polymer properties, such as stiffness and tensile strength, permeability, flame and scratch resistance as well as thermal stability ${ }^{21}$ and reported to improve the mechanical properties of the reinforced rubber- $\mathrm{CaCO}_{3}$ composites ${ }^{22,23}$.

Only few articles have reported the incorporation of both micron and nanosized particles into the same polymer composites. Zhang et al., showed that the mechanical property of polypropylene (PP) improved once $5 \mathrm{wt} \%$ nano- and $15 \mathrm{wt} \%$ micro particles of $\mathrm{CaCO}_{3}$ are filled into $\mathrm{PP}^{24}$. To the best of our knowledge there is no report on the incorporation of nano $\mathrm{CaCO}_{3}$ in the flame retardant natural rubber/expandable graphite formulations. 
The main object of our work is to study the effect of different loadings of nano $\mathrm{CaCO}_{3}$ on the cure and mechanical properties of the natural rubber/expandable graphite vulcanizates loaded with the $10 \mathrm{phr}$ of the flame retardant, expandable graphite. The results were then compared with vulcanizates loaded with precipitated calcium carbonate (PCC). The effect of loading of fillers on the natural rubber/expandable graphite composites, was studied by evaluating the cure, mechanical and swelling properties of the composites.

\section{EXPERIMENTAL}

Natural rubber (RSS5) was supplied by rubber chemicals, Kottayam, India. Common chemicals such as stearic acid, zinc oxide, accelerator F (mercaptobenzothiazyl disulphide and diphenyl guanidine), sulphur, 2,2,4-trimethyl-1,2-dihydroquinoline (TDQ) were of commercial grade. Precipitated calcium carbonate (PCC) was supplied by India Rubber Chemicals, Kottayam, India. Calcium chloride dihydrate, potassium carbonate and polyethylene glycol (PEG, molecular weight 6000) were procured from Merck Specialities Pvt. Ltd., India. The linseed oil was supplied by Laboratory Equipments, Kerala, India. Expandable graphite (Flexifoil-200) was supplied by Metachem Manufacturing and Company Pvt. Ltd., India.

Synthesis of nano $\mathrm{CaCO}_{3}$ : $\mathrm{Nano} \mathrm{CaCO}_{3}$ was synthesized by in situ precipitation method as reported elsewhere ${ }^{25}$. The calcium chloride solution was added drop-wise to PEG solution to form a complex and the calcium to PEG molar ratio was 1:4. The complex of $\mathrm{CaCl}_{2}$ and PEG was kept overnight. Potassium carbonate solution was then added slowly to the PEG-CaCl $\mathrm{Cl}_{2}$ complex while strong mechanical stirring. Slow appearance of a white precipitate indicated the formation $\mathrm{CaCO}_{3}$. The slurry was kept overnight for complete precipitation and ageing. The $\mathrm{CaCO}_{3}$ precipitate was filtered, washed with distilled water and dried.

Compound preparation: The vulcanizates of natural rubber with different fillers were prepared by roll milling where the mixing of polymer and other ingredients was accomplished by squeezing the stock between two rolls (diameter: $150 \mathrm{~mm}$ ) at $24 \mathrm{rpm}$. Mastication for each mix was done as per the composition given in Table-1. The nano- $\mathrm{CaCO}_{3}$, precipitated $\mathrm{CaCO}_{3}$, natural rubber and expandable graphite used in this study have been coded as C, P, N and G, respectively. The loadings (phr) have been indicated by the numbers next to the component code.
Cure characteristics: The processing time for each mix was maintained at 20-30 min depending on filler loading. Rheometric properties such as cure time, $\mathrm{t}_{90}$ (time required for a given compound to achieve $90 \%$ of the final delta torque value at a given temperature), maximum and minimum torques ( $\mathrm{MH}$ and $\mathrm{ML}$ ) and scorch time ( $\mathrm{ts}_{2}$, the time taken for two unit rise in torque above minimum torque, i.e., ca. $10 \%$ vulcanization) of the vulcanizates were studied by using a Mosanto moving die rheometer, (MDR 2000). The vulcanization of the rubber mixes was performed on a hydraulic press (platen size $\left.8^{\prime} \times 8^{\prime}\right)$ under 30 tonne pressure at $150^{\circ} \mathrm{C}$ according to their respective $t_{90}$ values.

Mechanical properties: Tensile strength of the vulcanizates was measured by using Instron 4411 Universal Testing Machine (Instron Ltd., Buckinghamshire, UK) at a cross head speed of $500 \mathrm{~mm} \mathrm{~min}^{-1}$. The tensile experiments were conducted according to the ASTM D 412-87 test procedures using dumb-bell shaped test pieces. The tear strengths were estimated following ASTM D 624-81 using unnicked $90^{\circ}$ angle test pieces. The hardness (Shore A) of the samples was measured according to ASTM 2240-86 procedure using a Durometer (Modex India Pvt. Ltd., India). All the results reported are the averages of five measurements.

Hardness: The hardness test of a rubber is the relative resistance of the surface to indentation by an indenter of specified dimension under a specified load. The hardness (Shore A) of the samples was measured using a Durometer (Modex India Pvt. Ltd., Mumbai, India) according to ASTM 2240-86.

Swelling beahviour: Equilibrium swelling of test pieces was carried out in toluene. The initial weight of the samples was taken and then introduced into toluene. These were removed periodically from the bottles, the adhering solvent was cleaned from the surface and then the sample was weighed immediately and then placed again into the toluene. The weight swelling ratio, $Q_{t}$ was determined from the weight of the sample in the unswollen and swollen states. The weight swelling ratio $\left(Q_{t}\right)$ was thus calculated using the equation

$$
\mathrm{Q}_{\mathrm{t}}=\frac{\mathrm{M}_{\mathrm{t}}-\mathrm{M}_{0}}{\mathrm{M}_{0}} \times 100
$$

where, $\mathrm{M}_{\mathrm{t}}$ is the weight of the sample in the swollen state and $\mathrm{M}_{\mathrm{o}}$ the initial weight of the samples. All tests were performed at room temperature $\left(25^{\circ} \mathrm{C}\right)$ and the reported results were averaged from a minimum of three specimens.

\begin{tabular}{|c|c|c|c|c|c|c|c|c|c|c|c|}
\hline \multicolumn{12}{|c|}{$\begin{array}{c}\text { TABLE-1 } \\
\text { COMPOUNDING RECIPE }\end{array}$} \\
\hline Ingredients (phr)* & $\mathrm{C}_{0}$ & $\mathrm{C}_{2}$ & $\mathrm{C}_{4}$ & $\mathrm{C}_{6}$ & $\mathrm{C}_{8}$ & $\mathrm{C}_{10}$ & $\mathrm{P}_{2}$ & $\mathrm{P}_{4}$ & $\mathrm{P}_{6}$ & $\mathrm{P}_{8}$ & $\mathrm{P}_{10}$ \\
\hline $\mathrm{NR}$ & 100 & 100 & 100 & 100 & 100 & 100 & 100 & 100 & 100 & 100 & 100 \\
\hline Zinc oxide & 5.0 & 5.0 & 5.0 & 5.0 & 5.0 & 5.0 & 5.0 & 5.0 & 5.0 & 5.0 & 5.0 \\
\hline Stearic acid & 3.0 & 3.0 & 3.0 & 3.0 & 3.0 & 3.0 & 3.0 & 3.0 & 3.0 & 3.0 & 3.0 \\
\hline TDQ & 1.0 & 1.0 & 1.0 & 1.0 & 1.0 & 1.0 & 1.0 & 1.0 & 1.0 & 1.0 & 1.0 \\
\hline Accelerator F & 1.5 & 1.5 & 1.5 & 1.5 & 1.5 & 1.5 & 1.5 & 1.5 & 1.5 & 1.5 & 1.5 \\
\hline Nano $\mathrm{CaCO}_{3}$ & - & 2.0 & 4.0 & 6.0 & 8.0 & 10.0 & - & - & - & - & - \\
\hline PCC & - & - & - & - & - & - & 2.0 & 4.0 & 6.0 & 8.0 & 10.0 \\
\hline EG & 10.0 & 10.0 & 10.0 & 10.0 & 10.0 & 10.0 & 10.0 & 10.0 & 10.0 & 10.0 & 10.0 \\
\hline Linseed oil & 2.0 & 2.0 & 2.0 & 2.0 & 2.0 & 2.0 & 2.0 & 2.0 & 2.0 & 2.0 & 2.0 \\
\hline Sulphur & 2.0 & 2.0 & 2.0 & 2.0 & 2.0 & 2.0 & 2.0 & 2.0 & 2.0 & 2.0 & 2.0 \\
\hline
\end{tabular}




\section{RESULTS AND DISCUSSION}

Nanoparticle characterization: Fig. 1 shows an XRD pattern for $\mathrm{CaCO}_{3}$ synthesized in PEG. Nano size $\mathrm{CaCO}_{3}$ was confirmed by the XRD pattern with Scherrer's formula:

$$
\mathrm{d}(\AA)=\frac{\mathrm{k} \lambda}{\Delta 2 \theta \cos \theta}
$$

where $\mathrm{d}$ is the particle size, $\mathrm{k}$ is the order of reflection, $\lambda$ is 1.542 and $\theta$ is the diffraction angle. The particle size was an average of $20 \pm 5 \mathrm{~nm}$

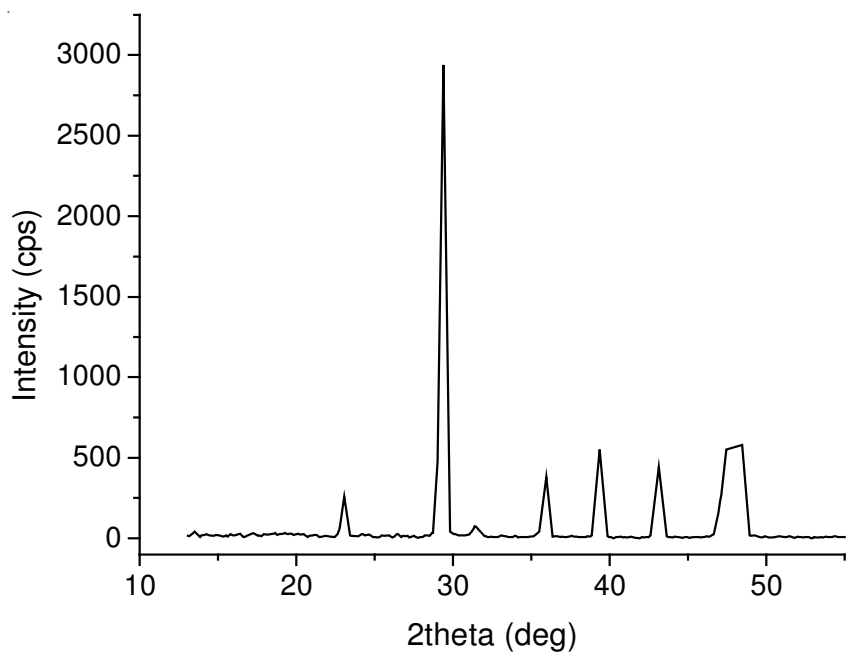

Fig. 1. XRD of nano- $\mathrm{CaCO}_{3}$

Cure characteristics: The cure characteristics of natural rubber/expandable graphite vulcanizates with different loadings of nano $\mathrm{CaCO}_{3}$ and precipitated calcium carbonate are given in Table-2. The vulcanizates with nano $\mathrm{CaCO}_{3}$ interestingly showed fast curing time, $t_{90}$ compared to the one with precipitated calcium carbonate. However, in the present study, the most probable factors to account for the observed cure enhancement of nano filler over precipitated calcium carbonate are surface area, surface reactivity and particle size. It is believed that the smaller the particle size, hence larger surface area, the greater the interaction between the filler and rubber matrix. The high specific surface area of nano $\mathrm{CaCO}_{3}$, imparts the vulcanizates with the highest viscosity and, thus, the highest temperature rise during mixing and as a result curing process is accelerated. The viscosity of the composite increases with increasing filler content and hence the cure time also decreases. This may be one of the reasons for reduced cure time for the compounds containing nano $\mathrm{CaCO}_{3}$. Scorch time indicates the period for which a compound can be stored safely before vulcanization. It also shows whether the compound is processable at higher temperatures. The data given in Table-2 indicate that addition of filler in rubber compounds reduces the scorch time. Among the fillers, precipitated calcium carbonate incorporated compounds showed slightly lower scorch time compared with those containing nano $\mathrm{CaCO}_{3}$. However, the difference in scorch times of the filled compounds is only marginal and the value indicate that there is adequate scorch safety for the compounds so that these can be stored or processed without any difficulty. MH-ML value
TABLE-2

CURE CHARACTERISTICS

\begin{tabular}{cccccc}
\hline $\begin{array}{c}\text { Sample } \\
\text { code }\end{array}$ & $\begin{array}{c}\text { Optimum } \\
\text { cure time } \\
\mathrm{t}_{90}(\mathrm{~min})\end{array}$ & $\begin{array}{c}\text { Scorch } \\
\text { time } \mathrm{ts}_{2} \\
(\mathrm{~min})\end{array}$ & $\begin{array}{c}\text { Minimum } \\
\text { torque ML } \\
(\mathrm{dNm})\end{array}$ & $\begin{array}{c}\text { Maximum } \\
\text { torque MH } \\
(\mathrm{dNm})\end{array}$ & $\begin{array}{c}\text { MH-ML } \\
(\mathrm{dNm})\end{array}$ \\
\hline $\mathrm{C}_{0}$ & 5.33 & 2.11 & 0.46 & 7.92 & 7.46 \\
$\mathrm{C}_{2}$ & 5.10 & 2.04 & 0.18 & 7.83 & 7.65 \\
$\mathrm{C}_{4}$ & 4.56 & 1.55 & 0.28 & 7.54 & 7.26 \\
$\mathrm{C}_{6}$ & 4.43 & 1.45 & 0.13 & 7.82 & 7.69 \\
$\mathrm{C}_{8}$ & 4.39 & 1.43 & 0.21 & 7.81 & 7.60 \\
$\mathrm{C}_{10}$ & 4.03 & 1.40 & 0.23 & 7.80 & 7.57 \\
$\mathrm{P}_{2}$ & 5.30 & 2.40 & 0.07 & 6.14 & 6.07 \\
$\mathrm{P}_{4}$ & 5.21 & 2.11 & 0.13 & 7.14 & 7.01 \\
$\mathrm{P}_{6}$ & 5.12 & 2.20 & 0.17 & 7.81 & 7.64 \\
$\mathrm{P}_{8}$ & 5.14 & 2.18 & 0.14 & 7.77 & 7.63 \\
$\mathrm{P}_{10}$ & 5.04 & 2.35 & 0.18 & 7.69 & 7.51 \\
\hline
\end{tabular}

indicates change in modulus due to extent of cross-linking and reinforcement by fillers. At equal volume loadings, compounds containing nano $\mathrm{CaCO}_{3}$ showed higher $\mathrm{MH}-\mathrm{ML}$ values compared with those containing precipitated calcium carbonate especially at higher loadings. This indicated higher level of reinforcement by nano $\mathrm{CaCO}_{3}$. It can be seen that $\mathrm{MH}-\mathrm{ML}$ increases with increasing nano- $\mathrm{CaCO}_{3}$ contents in the natural rubber/expandable graphite vulcanizates and decreases at higher loading indicating lower level of reinforcement, due to agglomeration of particles. The torque difference is a measure of the shear dynamic modulus, which indirectly relates to the crosslink density of the vulcanizates. Hence, it can be concluded that the incorporation of $6 \mathrm{phr}$ of nano- $\mathrm{CaCO}_{3}$ in the natural rubber/expandable graphite vulcanizates has contributed to a better cross-linking.

\section{Mechanical properties}

Tensile strength: It was observed that the tensile strength (TS) of the nano $\mathrm{CaCO}_{3}$ filled natural rubber/expandable graphite vulcanizates were higher than that of the composites with precipitated calcium carbonate (Fig. 2). The tensile strength of the natural rubber/expandable graphite/nano $\mathrm{CaCO}_{3}$ vulcanizates increased initially and showed a maximum value at $6 \mathrm{phr}$ filler loading and decreased subsequently. Results of nano filler is not appreciable above 6 phr loading, because the nano particles get agglomerated at higher loading of $\mathrm{CaCO}_{3}$. At 6 phr loading of nano $\mathrm{CaCO}_{3}$ and precipitated calcium

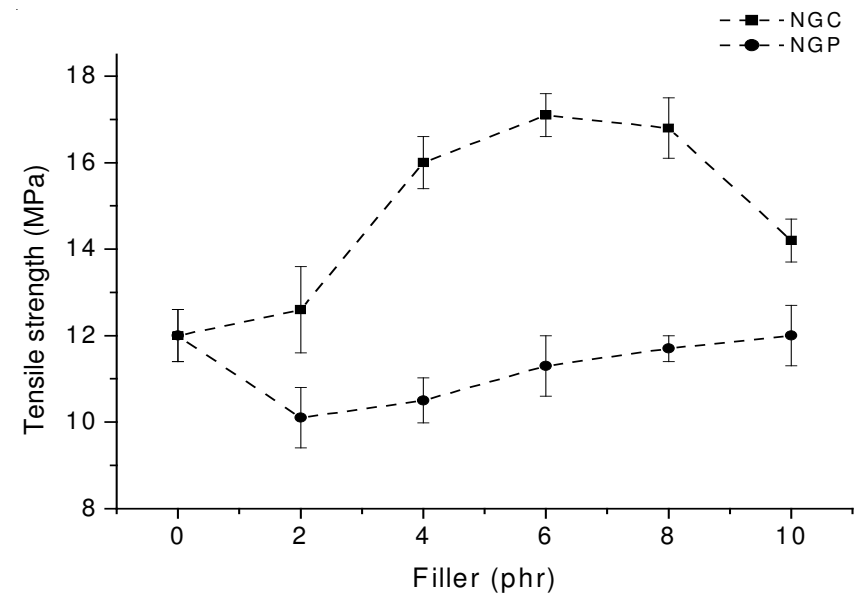

Fig. 2. Effect of filler contents on the tensile strength of the natural rubber/ expandable graphite vulcanizates 
carbonate filler, the tensile strength was recorded to be 17.19 and $11 \mathrm{MPa}$, respectively. The rate of increment in tensile strength was much higher for nano- $\mathrm{CaCO}_{3}$ filled composites. The higher value shown by nano $\mathrm{CaCO}_{3}$ filled composites can be attributed to the larger surface area, resulting in the intercalation and thereby increasing the cross-linking of polymer chains which facilitated effective stress transfer to the reinforcement phase.

Tear strength: Fig. 3. demonstrates the effect of addition of different loading of fillers on tear strength of natural rubber composites. As can be seen, the natural rubber/expandable graphite with nano $\mathrm{CaCO}_{3}$ exhibited higher tear strength compared to precipitated calcium carbonate filled vulcanizates. An initial increase in the tear strength was observed with the increase in the loading of nano $\mathrm{CaCO}_{3}$ up to $6 \mathrm{phr}$, which decreased subsequently with higher loadings. The increase in tear strength is mainly attributed to the reduction in stress concentration at the crack tips in the presence of nano fillers and is directly related to the strong interaction between the nano $\mathrm{CaCO}_{3}$ and the polymer matrix. However, at higher loadings, beyond $6 \mathrm{phr}$ of nano $\mathrm{CaCO}_{3}$, agglomeration of particles may act as strong stress concentrators and thereby promote catastrophic failure, thereby reducing the tear strength. The results imply that the most important factor controlling the tear strength of the composite is the specific surface area of the filler. However, at higher loadings, beyond $6 \mathrm{phr}$ of nano- $\mathrm{CaCO}_{3}$, agglomeration of particles may act as strong stress concentrators reducing the tear strength and thereby promote catastrophic failures.

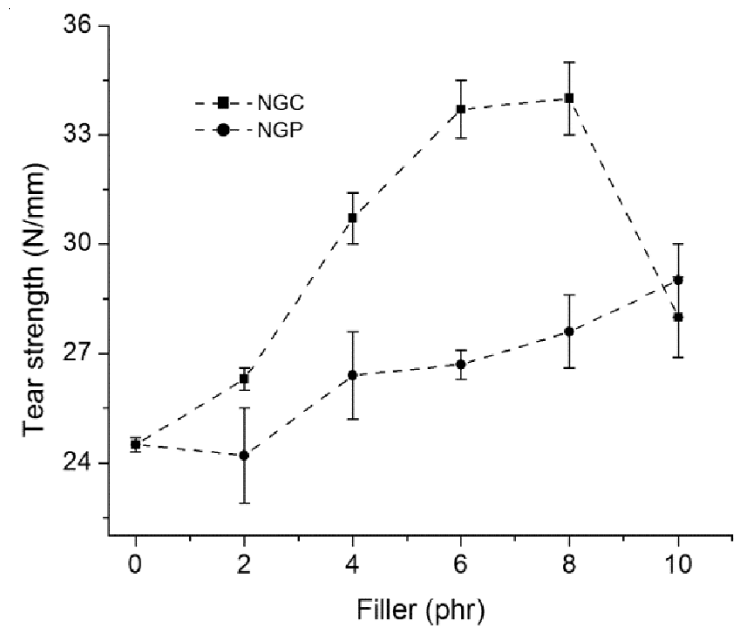

Fig. 3. Effect of filler loading on the tear strength of natural rubber/ expandable graphite vulcanizates

Elongation at break: The relationship between elongation at break (EB) and different loadings of nano $\mathrm{CaCO}_{3}$ and precipitated calcium carbonate in natural rubber/expandable graphite vulcanizates is presented in Fig. 4. The increment in elongation at break of nano $\mathrm{CaCO}_{3}$ filled vulcanizate is significantly greater than the precipitated calcium carbonate filled vulcanizates. At a loading of $6 \mathrm{phr}$, nano $\mathrm{CaCO}_{3}$ shows $580 \%$ elongation at break whereas, the precipitated calcium carbonate showed $490 \%$. This effect is due to very fine size of the particles, which produce more interfacial bonding and causes the molecular mobility to decrease resulting in the stiffening of the

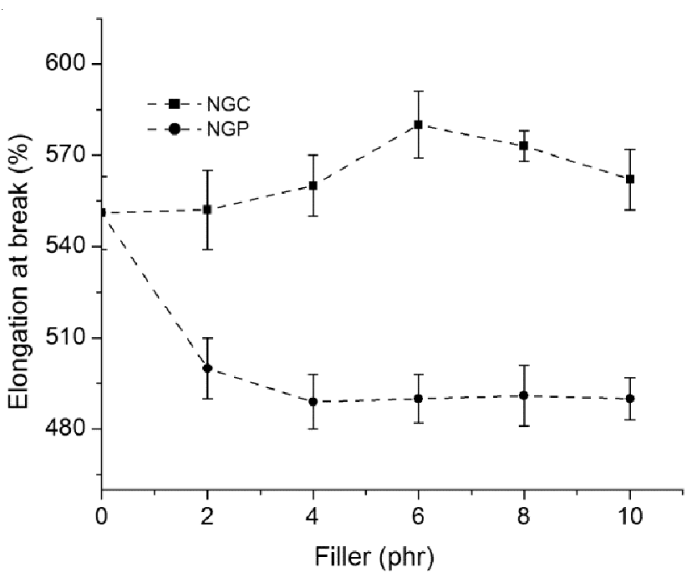

Fig. 4. Elongation at break of natural rubber/expandable graphite vulcanizates as a function of filler loading

matrix. As precipitated calcium carbonate possesses a very low specific surface area, when incorporated into natural rubber/ expandable graphite composites causes severe reduction of the elongation at beak.

Modulus: Modulus at $100 \%$ of natural rubber/expandable graphite filled with nano $\mathrm{CaCO}_{3}$ and precipitated calcium carbonate are shown in Fig. 5. The modulus of nano filler composites increases with increase up to $6 \mathrm{phr}$ of filler loading. The increment in modulus is significantly greater than the precipitated calcium carbonate filled natural rubber/expandable graphite. For $6 \mathrm{phr}$ of nano $\mathrm{CaCO}_{3}$ loading, the modulus is found to be $1.13 \mathrm{MPa}$. While the modulus for precipitated calcium carbonate filled natural rubber/expandable graphite is $0.89 \mathrm{MPa}$. This effect is due to the better interaction between the filler and the matrix as the nano fillers have high surface area compared to conventional fillers, therefore there is a better chance for good interaction. The graph clearly shows that at a particular loading, the natural rubber/expandable graphite/nano $\mathrm{CaCO}_{3}$ vulcanizates exhibits higher modulus than the natural rubber/expandable graphite/precipitated calcium carbonate vulcanizates. The modulus of natural rubber/expandable graphite vulcanizates, showed an optimum value at a loading $6 \mathrm{phr}$ of nano $\mathrm{CaCO}_{3}$. However beyond this filler content there appears

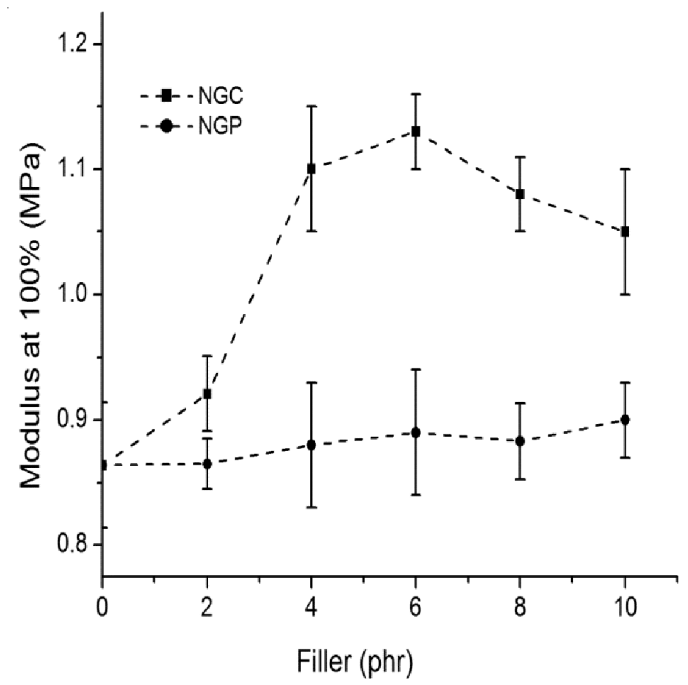

Fig. 5. Effect of filler loading on the modulus at $100 \%$ of natural rubber/ expandable graphite vulcanizates 
to be a decrease in the value. The improvement in the modulus at low nano filler content is attributed to the high resistance exerted by the nano filler against deformation. The improvement in the modulus at low nanofiller content is attributed to the high resistance exerted by the nanofiller against deformation. At higher filler content, the particles form agglomerates which reduce the adhesion between the filler and the matrix, thus decreasing the modulus.

Hardness: The change in hardness with different loadings of fillers in the natural rubber/expandable graphite vulcanizates is shown in the Fig. 6. It was observed that the hardness increased with an increase in the loading of fillers in nano and precipitated calcium carbonate filled vulcanizates. The increase in hardness was more pronounced for nano $\mathrm{CaCO}_{3}$ than for the precipitated calcium carbonate. It is attributed to the strong interaction between the nano filler and the polymer matrix.

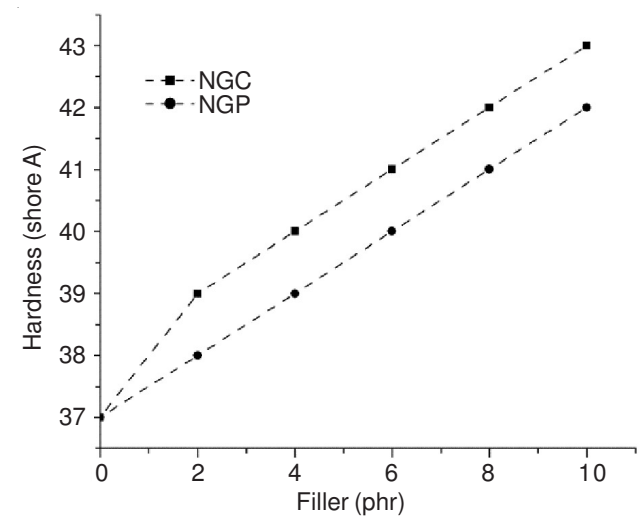

Fig. 6. Effect of filler loading on the hardness of natural rubber/expandable graphite vulcanizates

Swelling behaviour: The swelling behaviour of natural rubber/expandable graphite composites with different fillers are shown in Fig. 7. The swelling ratio of the vulcanizates with nano $\mathrm{CaCO}_{3}$ decreased in comparison with that of vulcanizates with precipitated calcium carbonate. With $10 \mathrm{phr}$ filler, the swelling ratios were 314 and $330 \%$ for nano $\mathrm{CaCO}_{3}$ and precipitated calcium carbonate, respectively. The decrease in swelling ratio with increasing nano filler loading may be that the nano particles behave as an obstacle to the diffusing molecule. As filler loading increases in rubber matrix more and more obstacles are created to the diffusing molecule.

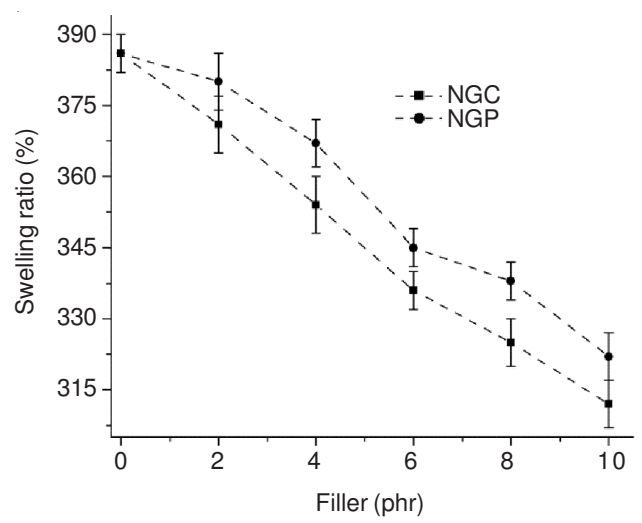

Fig. 7. Swelling ratio of natural rubber/expandable graphite composite with fillers at various compositions

\section{Conclusion}

The cure and mechanical properties of nano $\mathrm{CaCO}_{3}$ on the flame retardant expandable graphite filled natural rubber vulcanizates have been studied. The results indicated that incorporation of nano $\mathrm{CaCO}_{3}$ in mechanical property-wise inferior expandable graphite treated natural rubber composites has enhanced the cure properties, tensile strength, tear strength, elongation at break, modulus and swelling behaviour significantly. The results were also compared with precipitated calcium carbonate filled natural rubber/expandable graphite composites. Among the fillers, the nano $\mathrm{CaCO}_{3}$ filled natural rubber/expandable graphite showed better enhancement of the properties in comparison with precipitated calcium carbonate filled composites. Because of the smaller size and high surface area, a large extent of rubber intercalation into the nano particles might have provided a strong rubber filler interaction. The natural rubber/expandable graphite composites with $6 \mathrm{phr}$ of nano $\mathrm{CaCO}_{3}$ showed optimum mechanical properties. This improvement in the cure and mechanical properties of the natural rubber/expandable graphite composites can be advantageous in the areas where rubber components need high fire safety and better mechanical properties.

\section{ACKNOWLEDGEMENTS}

The authors thank the Director, Common facility Service Centre, Changanacherry, Kerala, India for granting permission to use the laboratory facilities for the research work.

\section{REFERENCES}

1. D. Derouet, N. Radhakrishnan, J.C. Brosse and G. Boccaccio, J. Appl. Polym. Sci., 52, 1309 (1994).

2. M.T. Ramesan, React. Funct. Polym., 59, 267 (2004).

3. R.C. Xie and B.J. Qu, J. Appl. Polym. Sci., 80, 1181 (2001).

4. R.C. Xie and B.J. Qu, J. Appl. Polym. Sci., 80, 1190 (2001).

5. C.H. Chen, W.H. Yen, H.C. Kuan, C.F. Kuan and C.L. Chiang, Polym. Composite, 31, 18 (2010).

6. L. Ye, X.Y. Meng, X. Ji, Z.M. Li and J.H. Tang, Polym. Degrad. Stab., 94, 971 (2009).

7. F.M. Uhl, Q. Yao, H. Nakajima, E. Manias and C.A. Wilkie, Polym. Degrad. Stab., 89, 70 (2005).

8. J. Yang, M. Tian, Q.S. Jia, L.Q. Zhang and X.L. Li, J. Appl. Polym. Sci., 102, 4007 (2006).

9. S. Moon, B. Jo and R.J. Farris, Polym. Composite, 30, 1732 (2009).

10. Y.F. Shih, Y.T. Wang, R.J. Jeng and K.M. Wei, Polym. Degrad. Stab., 86, 339 (2004).

11. Y.F. Shih, Macromol. Chem. Phys., 206, 383 (2005).

12. H.F. Zhu, Q.L.Zhu, J.A. Li, K. Tao, L.X. Xue and Q. Yan, Polym. Degrad. Stab., 96, 183 (2011).

13. M. Modesti and A. Lorenzetti, Polym. Degrad. Stab., 78, 341 (2002).

14. B.J. Qu and R.C. Xie, Polym. Int., 52, 1415 (2003).

15. L. Shi, Z.M. Li, B.H. Xie, J.H. Wang, C.R. Tian and M.B. Yang, Polym. Int., 55, 862 (2006).

16. L. Shi, Z.M. Li, M.B. Yang, B. Yin, Q.M. Zhou, C.R. Tian and J.-H. Wang, Polym-Plast. Technol. Eng., 44, 1323 (2005).

17. X.C. Bian, J.H. Tang, Z.M. Li, Z.Y. Lu and A. Lu, J. Appl. Polym. Sci., 104, 3347 (2007).

18. X.C. Bian, J.H. Tang and Z.M. Li, J. Appl. Polym. Sci., 109, 1935 (2008).

19. X.C. Bian, J.H. Tang and Z.M. Li, J. Appl. Polym. Sci., 110, 3871 (2008).

20. M. Modesti and A. Lorenzetti, Eur. Polym. J., 39, 263 (2003).

21. M. Avella, M.E. Errico and E. Martuscelli, Nano. Lett., 1, 213 (2001).

22. C.H. Chen, C.C. Teng, S.F. Su, W.C. Wu and C.H. Yang, J. Polym. Sci. Pol. Phys., 44, 451 (2006).

23. C.M. Deng, M. Chen, N.J. Ao, D. Yan and Z.Q. Zheng, J. Appl. Polym. Sci., 101, 3442 (2006).

24. J. Zhang, B. Han, N.L. Zhou, J. Fang, J.A. Wu, Z.M. Ma, H. Mo and J. Shen, J. Appl. Polym. Sci., 119, 3560 (2011).

25. S. Mishra and N.G. Shimpi, J. Appl. Polym. Sci., 98, 2563 (2005). 